\title{
Relaxed molecular clocks for dating historical plant dispersal events
}

\author{
Susanne S. Renner
}

Department of Biology, Ludwig Maximilians University, D-80638 Munich, Germany

Age estimation from molecular sequences has emerged as a powerful tool for inferring when a plant lineage arrived in a particular area. Knowing the tenure of lineages within a region is key to understanding the evolution of traits, the evolution of biotic interactions, and the evolution of floras. New analytical methods model change in substitution rates along individual branches of a phylogenetic tree by combining molecular data with time constraints, usually from fossils. These 'relaxed clock' approaches can be applied to several gene regions that need not all have the same substitution rates, and they can also incorporate multiple simultaneous fossil calibrations. Since 1995, at least 100 plant biogeographic studies have used molecular-clock dating, and about a fifth has used relaxed clocks. Many of these report evidence of long-distance dispersal. Meta-analyses of studies from the same geographic region can identify directional biases because of prevailing wind or water currents and the relative position and size of landmasses.

Inferring past plant dispersal: from which data and why? The geographic ranges of the lineages seen today are often interrupted by large expanses of inhospitable habitat, for example, an ocean. This raises questions about how and when they acquired their disjunct habitats. When lineages arrive in new habitats they will usually diverge and sometimes speciate, therefore, dating dispersal and lineage splits has broad implications for understanding rates of diversification [1], the evolution of biota [2,3] and associated faunas [4-6], and the time taken for species to adapt to novel environments [7-10]. Recent biogeographic studies that have included time estimates have revealed strikingly fast diversification rates in some floras, such as the Cape Region of South Africa, the recency of species accumulation even in ancient lineages, such as ferns [1], and the persistence of precarious mutualisms over many millions of years, such as the interactions between figs and fig wasps and between yucca and yucca moths [4,6].

The ideal materials from which to estimate the ages of lineages and their presence in particular places are abundant fossils. However, isolated fossils often provide only screenshots from which we extrapolate in time and space. Extinction followed by recolonization is particularly difficult to infer from the fossil record. It is often more parsimonious to interpret the history of taxa with extended

Corresponding author: Renner, S.S. (renner@lrz.uni-muenchen.de).

Available online 12 October 2005 fossil records in a framework of continuity [11,12]. Yet, there is ample direct evidence of rapid species expansions following dispersal from the study of invasive species, phylogeographic molecular data, and natural experiments such as Krakatau, an island sterilized by a massive eruption in 1883 [13-16].

The idea of dating the divergence of lineages from the time-dependent change of their genomes, the molecular clock hypothesis, is 40 years old [17], and plant geographers have applied sequence- or protein-based dating since the 1990s [18-28]. With increasing computer power and access to readily implemented molecular evolutionary

\footnotetext{
Glossary

Chronogram: a phylogenetic tree in which branch lengths correspond to time. Crown group: any node in a phylogeny with two or more descendent branches reaching the present.

Gene coalescence: coalescence theory examines the genealogical relationships between copies of genes in a sample. It assumes that all alleles in an extant pool must have descended from a single allele (to which they coalesce). For neutral nuclear alleles in a random mating population, the mean coalescence time is given by $4 N[1-(1 / i)]$ generations, where $i$ is the number of sampled gene copies. Chloroplast or mitochondrial genes have mean coalescence times of $N[1-(1 / i)]$, rather than $4 N[1-(1 / i)]$.

Genetic distance: refers to the number of substitutions at which two sequences differ. Rather than simply taking the observed number, one calculates a more likely number by assuming an underlying nucleotide substitution model, based on what is known about the specific genome region that was sequenced. Nucleotide substitution models: these models try to capture the probability of a nucleotide changing to another, using several variables, such as the frequency of the base, the mean mutation rate, and a modification of that mean rate, dependent upon the identity and position of the nucleotide (for example, if it is a purine or pyrimidine, or in the first, second or third position in the codons of coding genes).

Posterior rate: in Bayesian analysis of molecular data, the posterior (or posterior probability density) is the probability distribution over the parameter state space, given the data under a chosen model of evolution. In molecular clock work, the posterior rate is the parameter of the greatest interest because it allows the age of any node in the tree to be calculated.

Prior rate: in Bayesian analysis of molecular phylogenetic data, priors represent one's assumptions about the probabilities of different parameter values. The prior rate is calculated by dividing the median genetic distance from the root to the tips (terminal branches in the tree) by an assumed age of the root. This would amount to the entire analysis being circular were it not the case that prior assumptions can be greatly changed by the actual data, which comprise the nucleotide substitutions, one or multiple time constraints (from fossils), and a given topology.

Stem lineage: any branch in a phylogeny with two or more descendent branches. When using trees to develop evolutionary scenarios, one assumes that the various synapomorphic characters found in a group evolved somewhere along its stem lineage. The concept is extremely important when calibrating molecular clocks. This is because (the age of) a calibration fossil that has the synapomorphies of clade A should be used to constrain the node where the stem lineage of clade A diverges from its sister(s) (see also Figure 1). This is the only assignment of the fossil constraint that properly accounts for the fact that the apomorphic morphological traits of clade A evolved somewhere along its stem lineage. Not knowing exactly when that was, one lacks a criterion for
} assigning them to a particular place on the stem. 
models, the number of studies using genetic distances to calculate ages of dispersal events has mushroomed. Between 1992 and 1998, 20 phytogeographic papers used a clock approach. Over the past six years (to May 2005 ) that number has quadrupled, with more and more studies relying on relaxed clocks.

Molecular clock-based dating of divergence events (i.e. nodes in a phylogeny) involves the following steps: (i) obtaining the genetic distance (see Glossary) between two sequences or taxa in the analysis, one of which must have a known age (or age range), usually determined from fossils; (ii) calculating the substitution rate by dividing the genetic distance by the known age; (iii) using that rate to convert genetic distances between taxa of interest into estimates of their absolute ages. These steps are dealt with in the sections below.

Genetic distances between sequences are calculated using nucleotide substitution models. The distance unit is number of substitutions per nucleotide site or of substitutions per codon. The number of nucleotide substitutions is generally correlated with time because when changes are neutral (no selection), substitution is driven by mutation and genetic drift. Under selection, substitution between different parts of the genome, gene regions and organisms varies, but can nevertheless remain stable within some genes, sets of codons, or other types of data partition and within subsets of taxa. Local datasets (combinations of taxa and gene regions) can thus exhibit roughly regular, or clock-like, accumulation of substitutions [29-31]. However, it is clear that there is no universal clock [32,33].

Studies in plants have uncovered striking heterogeneity in the rate of nucleotide substitution among lineages [32,34]. Unfortunately, assessing the rate of heterogeneity is difficult because the power of relative rate tests or likelihood ratio tests depends on the amount of signal in the data. Where sequence divergence is low or sampled sequences are short, the power of these tests is correspondingly low [33,35]. Small datasets therefore sometimes satisfy the 'clock assumption' [i.e. the accumulation of substitutions does not differ statistically between sister-groups], but large variations (uncertainty) in estimates of branch lengths (and dates) weaken any conclusions [27,30,36-38].

\section{Problems from faulty branch-length estimation}

Molecular clock dating stands or falls with the accuracy with which genetic distances can be estimated. Contradictions between molecular clock-based age estimates and fossil-based estimates, and also between different dating approaches, have spurred efforts to understand their causes [39-41]. It is clear that dating biases can result from misspecification of genetic distances (branch-lengths in the trees), either because of incorrect topology among early-diverging branches or incorrect nucleotide substitution models. The parameter values estimated to represent the true substitution process are based on observed nucleotide (or amino acid) changes, which are produced through evolution with a high degree of stochasticity. Current models accommodate many aspects of heterogeneous substitution across sites, but because the same model or combination of models is used for all sequences in a dataset, heterogeneity among species cannot be dealt with beyond influencing average parameter values. Efforts are underway to improve models by including parameters for covariation between neighboring nucleotides and variation over time in nucleotide composition [31,42,43]. Assuming 'neighbor dependence' of nucleotides is the basis for accommodating rate heterogeneity between taxa, and therefore these models offer considerable promise for molecular age estimation.

Another problem is the choice of gene region on which to base the estimates. In theory, one can chose a level of phylogenetic resolution by sampling the gene regions that accumulate substitutions at an appropriate rate. In practice, biogeographers have little choice in the matter because of limited suitable material from rarely collected species in remote areas and because taxon sampling must be adapted to allow calibration. Direct calibration with preserved 'ancient' DNA is commonly used for emerging diseases, using frozen tissue samples [44]. In principle, this should be possible for plant tissues given that DNA can be obtained and sequenced from 17-million year (my)20-my-old fossils [45].

Calibration always involves dividing the genetic distance between two sequences by time (Figure 1). In biogeographic work, the time entered in this equation is usually the age of the oldest fossil of a close relative of the focal taxa. Where close relatives have no fossil record, biogeographic studies can require the inclusion of phylogenetically distant outgroups simply because they do have a fossil record. This can entail relying on conserved gene regions that are alignable across distant relatives and/or that are available from GenBank (when collecting certain taxa is not feasible). However, these more conserved regions might not be variable among the sister species whose divergence one wishes to date. The only way to proceed then is to analyze separate datasets and to bridge them by using one of the nodes dated in the first analysis as a calibration point in the second analysis (secondary calibration, e.g. [46,47]). Successive bridging is likely to compound the estimated error [48]. Extrapolation, and how much is acceptable, lies at the heart of all controversy surrounding the use of molecular clocks.

\section{Converting genetic distances to absolute times - the issue of calibration}

Besides erroneous branch-length estimation, another cause of discrepancies between fossil-based ages and molecule-based ages is the tenuous association between a node in a gene tree and the time point or time bracket used to convert (genetic) distance into rate. Genes evolve at different rates and, therefore, will reflect disruption of gene flow differently, with some coalescing long before and others long after the disrupting dispersal event. As long as sampling is appropriate to gene coalescence times, this presents no problem because clade divergence and gene divergence will at least have the same topology. However, many botanical molecular time estimates have relied on nuclear rDNA internal transcribed spacers (ITS), which are known to exist in paralogous copies that can persist 
(a)

Extant taxon

† Extinct taxon

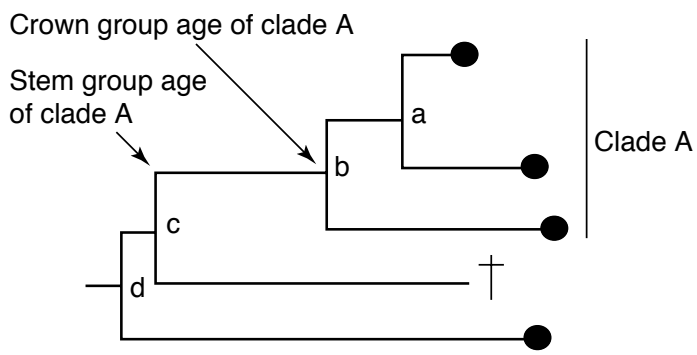

(c)

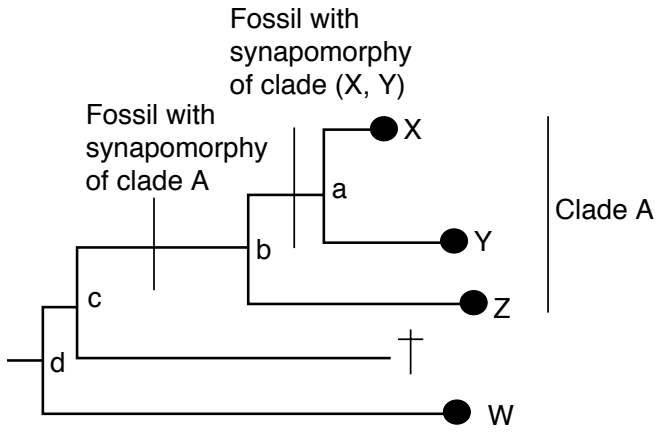

(b)

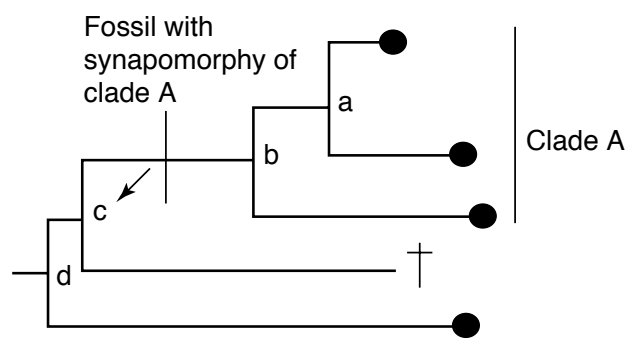

(d)

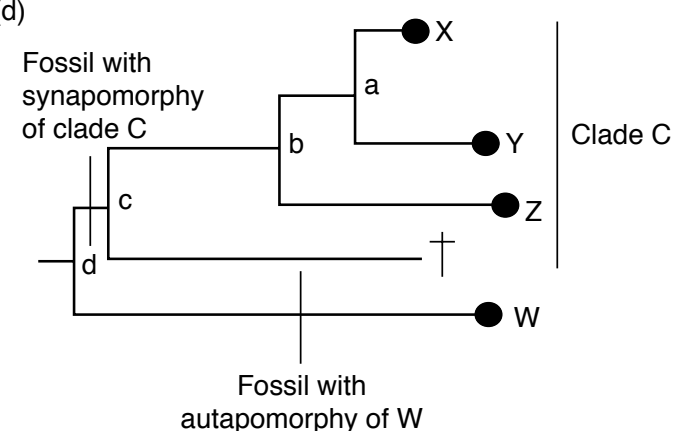

$\overline{\text { TRENDS in Plant Science }}$

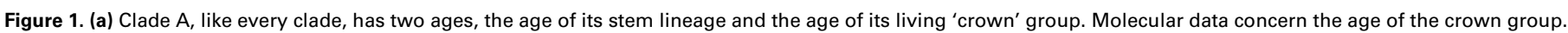

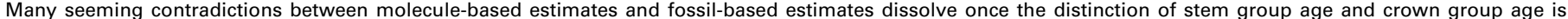

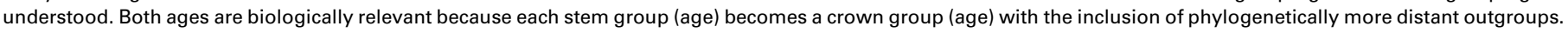

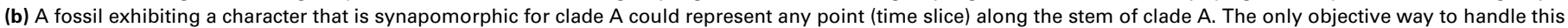

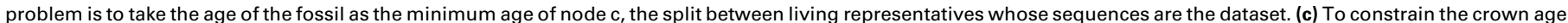

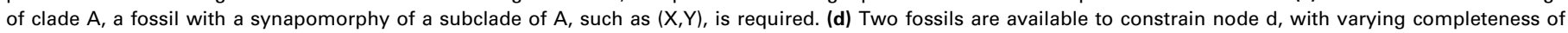

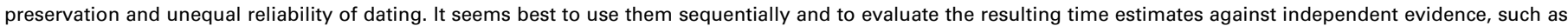

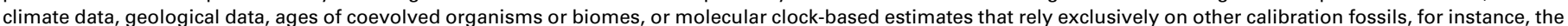
fossil of $(X, Y)$ used in (c).

through speciation events, and some such estimates might turn out to be erroneous.

An important concept relevant to calibration is the distinction between stem lineage and crown group [33,41, 49,50 ] (Figure 1a). For a fossil to be used for calibration, it must exhibit at least one trait that is synapomorphic for a clade in the tree. Such a fossil provides a minimum age for the node just below the clade whose synapomorphy it exhibits (Figure 1 lb and c). Fossils must be used in this conservative way because there is no objective criterion for assigning them 'somewhere' along stems (and stems can be long). When facing a choice between several fossils (Figure 1]d), one would choose the older, all else being equal, or perhaps explore their effects sequentially if they differ in reliability. [Figure 1] highlights that the use of multiple fossil dates reduces errors in calibration.

Of the $\sim 100$ plant geographic studies to date that have used strict or relaxed molecular clocks, more than half have relied on average substitution rates from other studies or have calibrated substitution rates by the ages of geological events, such as the ages of islands or the origin of a mountain chain, rather than by fossils, usually because suitable fossils were lacking. However, constraining nodes in a phylogenetic tree by geological events (e.g. [51]) risks circularity in biogeographic analyses because it already assumes that those events caused the divergence, rather than testing temporal coincidence. Geological events nevertheless provide an important validation of estimates reached by other calibrations [52-55]. This also seems the safest use of the ages of oceanic islands that have endemic taxa on them. Using island ages directly to constrain the ages of their endemic species overlooks the possibility that an insular endemic could have split from its mainland relative(s) before arriving on the island or that it might have arrived millions of years after the island originated. Only when an original colonist has diversified can the island age be used as a minimum age constraint. However, this strict criterion is not always used (e.g. [56,57]). Studies that have relied on fossil calibration points have generally found the age of island radiations to be younger than the islands they occupy [27,28,58,59]. An exception is the single Hawaiian species of Begoniaceae, Hillebrandia sandwicensis, which was dated to 51-my-65-my [60], older than even the sunken islands of the Hawaiian chain. However, the study relied on calibration with a fossil accepted as 55-my-old [61] but dated to 33-my by modern work. Applying the new calibration, as well as additional calibrations to an enlarged gene and taxon set [62], yields an age for the divergence of Hillebrandia from mainland relatives more 


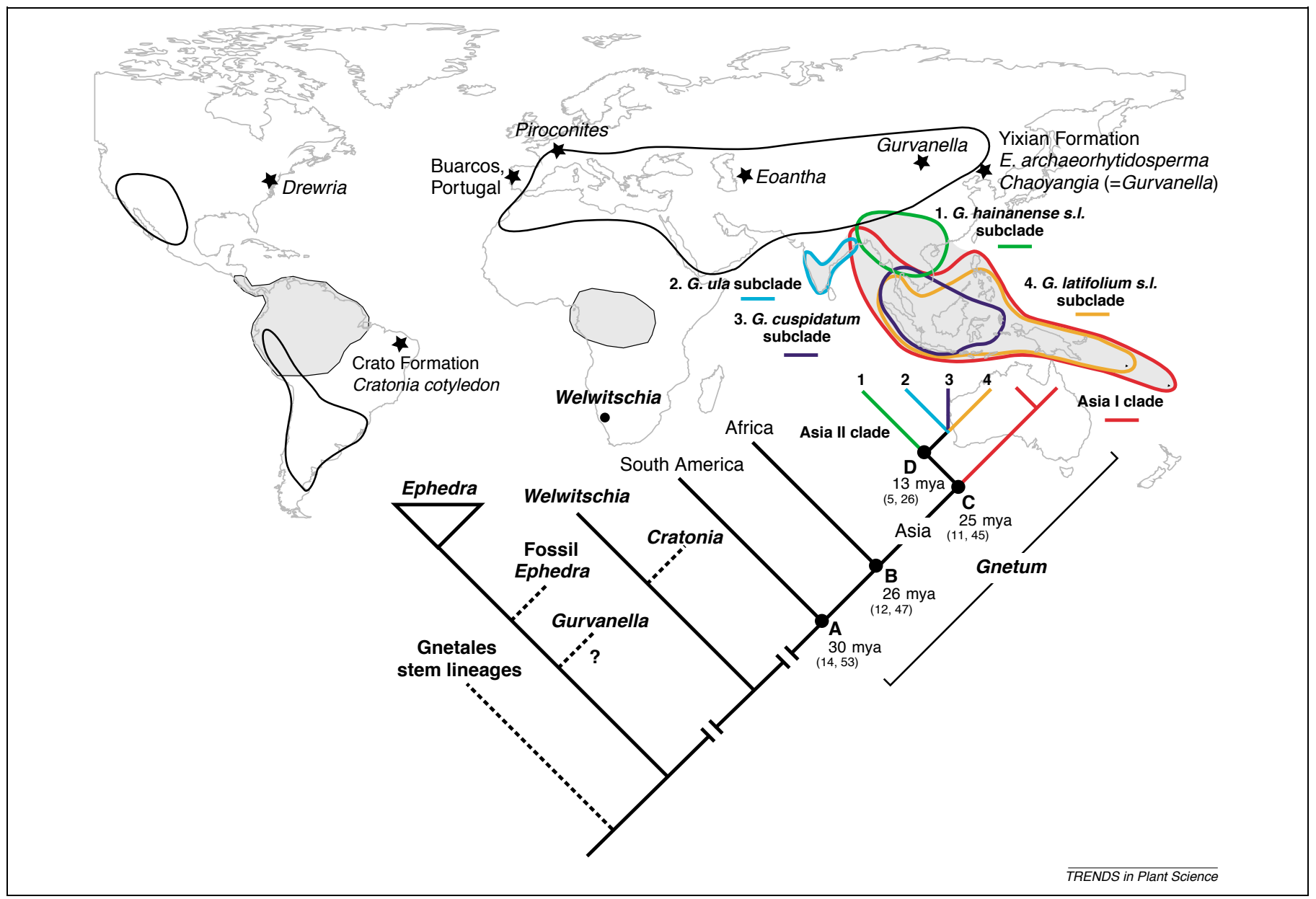

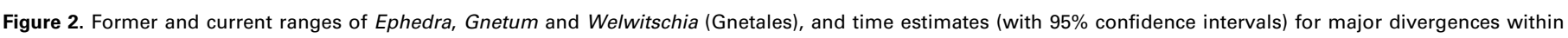

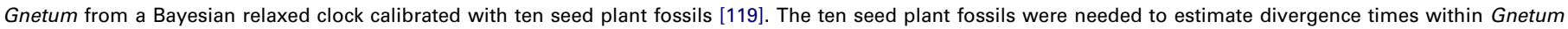

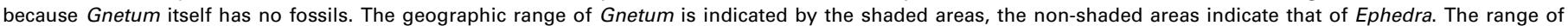

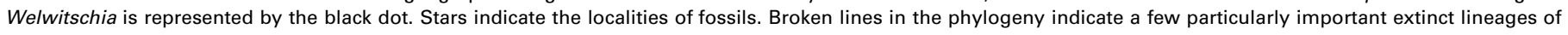
Gnetales.

in keeping with now submerged islands in the Hawaiian chain dating back 32-my [63]. A similar age has been estimated for the endemic Hawaiian fern Diellia [64], implying that the lineage jumped between islands as the Hawaiian chain evolved.

A final way to convert genetic distances into absolute time is to use the age of a habitat to which a clade is strongly adapted [27,65], but this approach can be misleading because the ages of many habitats are imprecisely known.

Given the difficulty of calibrating genetic distances to convert them into absolute times, it is clear why it is desirable to use multiple calibrations wherever possible. However, even with ancient and relatively good fossil records, such as those of Calycanthaceae, Chloranthaceae, Ephedra, Nothofagus or Nymphaeaceae, seeming contradictions between paleobotanical studies [11,12] and molecular clock studies can arise [47,66-69]. These dissolve when it is understood that the young molecular estimates for living clades in these families simply indicate that a diversification in an area is young (Figure 1a). Old lineages do not necessarily stop dispersing and diversifying. Striking examples of this are found among aquatic plants [69-72] and among the seed plant lineage Gnetales (Figure 2).

\section{Relaxing the clock assumption, multiple genes and simultaneous multiple calibrations}

Analytical methods that relax the assumption of rate constancy among lineages became available in 1997 [773], and several more have been introduced since then [36,37,74-76,120]". Rather than superimposing fossils on particular nodes in a phylogenetic tree, these methods use fossil dates to provide upper or lower bounds, or time brackets, on nodes. Several time brackets can be used sequentially or simultaneously, and it is helpful to have at least one constraint near the root of the tree and one nested among the tips.

Because of its straightforward use, most biogeographic studies have used the penalized likelihood (PL) approach [37,77-80]. Penalized likelihood assumes that substitution rates of ancestral and descendent lineages (about a node) are auto-correlated in time, and introduces a penalty for abrupt rate changes between them. Another

* Drummond, A.J. and Rambaut, A. (2005) BEAST v1.3, Available from http:/ evolve.zoo.ox.ac.uk/beast, 
approach to relaxing the clock assumption is to use 'local clocks' [76,81]. This method assumes that the ages of calibration nodes are known and then assigns different constant rates to different parts of the tree. It is suitable for lineages with well-understood fossil constraints [766,82,83].

Bayesian approaches to relaxing the clock are implemented in multidivtime [36,84,85], PhyBayes [75], and BEAST ${ }^{*}$. Because of the speed of the Markov chain Monte Carlo likelihood calculation, it is possible to simultaneously use branch lengths obtained from different genes (or data partitions, for example, first, second and third codon positions), each with its own fitted molecular evolutionary model. The idea is that single genes can be misleading about divergence times, but that combining multiple genes with different patterns of rate change introduces internal constraints and thus improves the extraction of information about the true organismal divergence time, which is presumed to lie somewhere in the middle. The approaches differ in that multidivtime and PhyBayes assume autocorrelated rate change, which in multidivtime is modeled as lognormally distributed, whereas in BEAST and PhyBayes the user can choose between different models of rate change, including lognormally distributed, gamma-distributed, and exponentially distributed change. BEAST version 1.3 , released on 30 August 2005, does not assume autocorrelated rate change (Table 1) and is the only software that can infer phylogenies under a relaxed clock model.

Studies that compared PL, Bayesian approaches and local clocks, using simulated and empirical data [82,86] found that local clock models and Bayesian approaches outperform PL under certain conditions. When data are clock-like, PL overestimates the rate, suggesting that the method might have an intrinsic bias; a similar effect was observed when data were not clock-like (a possible example of PL overestimation can be found in [55]). Empirical studies that applied PL, multidivtime, and the strict clock to the same data have not identified consistent differences [54,72,87-90]; all the methods sometimes overor underestimated ages as judged by oldest fossils. Given the nature of the fossil record, this is clearly not a valid test of inference methods. Of greater relevance is the finding that simulation studies for the Bayesian methods show that the choice of the prior rate has a considerable effect on posterior rate estimates, whereas empirical studies have found that widely different prior rates had almost no effect on estimated dates.

All current methods of relaxing the clock assumption recover reliable rates and ages only when several calibration points are accurate. In practice, uncertainties in calibrations owing to misidentified or misdated fossils [39,41,49,50] , taxon sampling effects [91], and asymmetric tree shape can reduce the reliability of date estimates. Where data are approximately clock-like, assuming a strict clock can be the best way to improve the precision and perhaps accuracy of rate and date estimates [37,86]; results from relaxed clocks

* Drummond, A.J. and Rambaut, A. (2005) BEAST v1.3, Available from http:/ evolve.zoo.ox.ac.uk/beast/ should always be evaluated in relation to those from strict clocks calibrated at single nodes.

The importance of large amounts of sequence data for narrowing confidence ranges is also becoming increasingly clear [38,90]. To calculate errors on branch lengths (and ages), most studies have followed a bootstrapping procedure [27,39]. When nucleotide substitutions are approximately normally distributed, standard deviations rather than confidence intervals have also been calculated [92,93]. An advantage of Bayesian approaches is that 95\% confidence intervals around age estimates are directly reported by available software. Another approach that provides confidence intervals around estimates is the mean path length method, which assumes a strict clock but allows multiple calibrations [94]

\section{Molecular clock-based biogeography Dispersal across the Northern temperate zone}

The striking similarities between the floras of North America and Asia have long drawn the attention of plant geographers. Do floristic similarities date back to Paleocene or Eocene times when warm climates would have permitted the crossing of the North Atlantic and Beringian land bridges or are they more recent, such that one has to assume island hopping across the North Atlantic or Beringia? This question is often answered in favor of a recent (Miocene) crossing [54,95-98]. However, a few plant disjunctions have been inferred to date back to the Eocene warm-temperate forest belt that extended from California through southeastern North America, Europe and the Mediterranean to eastern Asia, following the regression of the epicontinental Turgai Sea that had formerly separated Europe and Central Asia. Today, some of these taxa are restricted to the humid tropics; the new hypotheses about their northern routes from Asia to Europe and North America, and from there to South America or Africa, are in stark contrast to earlier suppositions about southern, Gondwana connections [79,92,93,99,100].

Long-distance dispersal in the Southern temperate zone Australasia is the part of the world where dispersal and vicariance explanations of historical biogeography have clashed most severely [101]. Molecular-clock dating for New Caledonia and New Zealand endemics, together with new fossils [102], indicates that in spite of the isolation of these islands for the past 85-my-65-my, their floras are mostly the result of Oligocene and more recent longdistance dispersal [102,103]. Striking cases include lineages of Sapotaceae [104], although calibration of the ITS sequences used is based on extrapolation from other plant families), Myosotis [105], Lepidium [106] and Nothofagus [68]. Nothofagus, which has an 80-my-old fossil record, is one of clearest examples of an ancient lineage with a complicated history of extinctions and new radiations, some of them following dispersal events, others probably relictual.

\section{Dispersal across the Atlantic}

Molecular clock-based divergence times for sister clades occurring on both sides of the Atlantic often implies 
Table 1. Programs for molecular clock-dating that relax the clock assumption of a homogeneous substitution rate ${ }^{a}$

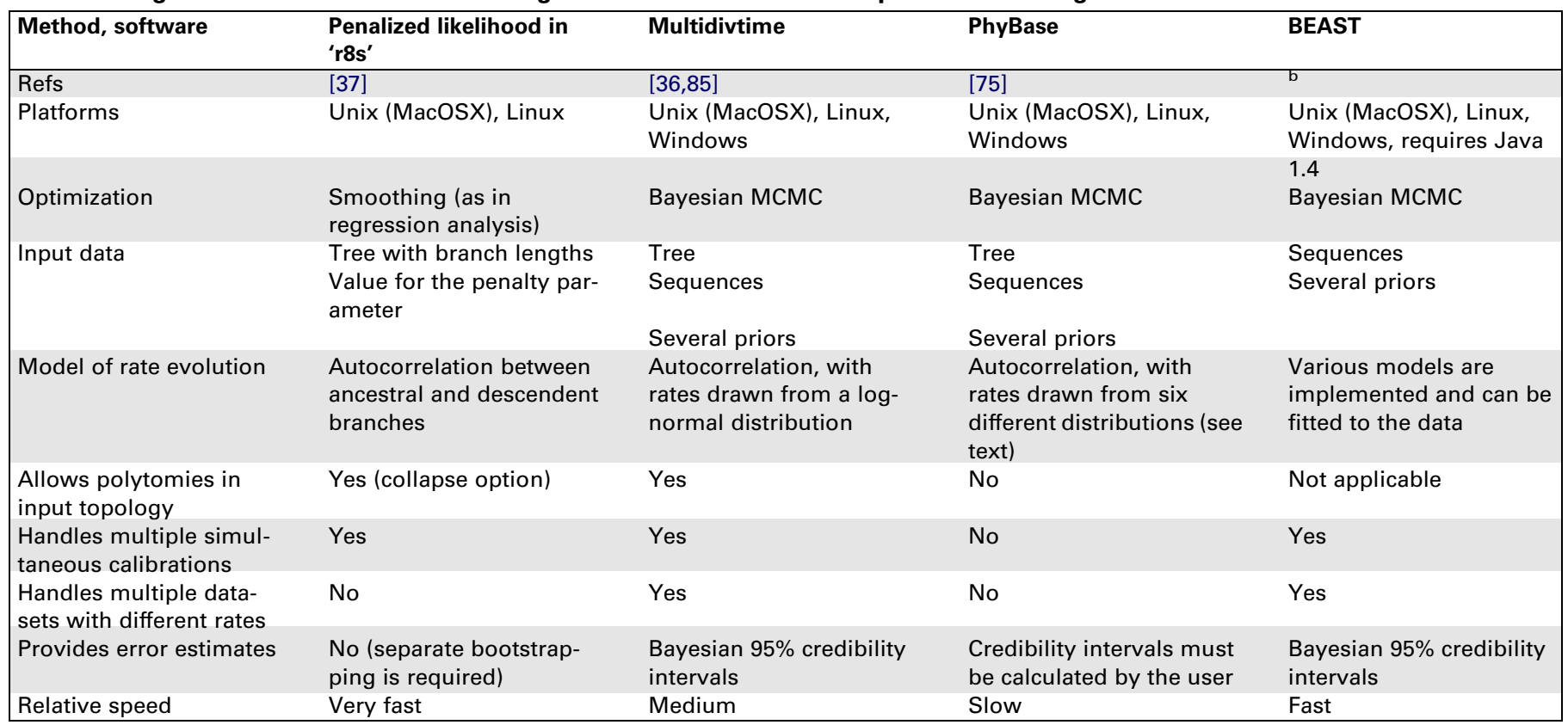

Abbreviation: Bayesian MCMC, Bayesian Markov chain Monte Carlo.

${ }^{a}$ Modified from a comparison that includes other approaches such as strict clocks, local clocks and nonparametric rate smoothing [121]

${ }^{b}$ Drummond, A.J. and Rambaut, A. (2005) BEAST v1.3, Available from http://evolve.zo0.ox.ac.uk/beast].

Oligocene and Miocene over-water dispersal [53,78,79,83, 92,107-109]. The genus Senecio alone contains several examples of dispersal from the Mediterranean or Africa to the New World [110], and the legume family adds another 30 to 40 cases [78]. However, $\sim 110$ angiosperm genera have trans-Atlantic disjunct species, and the disjunctions analyzed to date constitute only a small sample. This might explain why a search for directional biases from South America to Africa, or vice versa, has so far been fruitless [111].

Dispersal across the Indian Ocean and the tropical Pacific The close floristic ties between East Africa, the Seychelles, India and Southeast Asia, areas that were last physically connected in the Cretaceous, have been attributed recently to dispersal across the Indian Ocean [26,79,83, $88,112,113]$. The idea of a taxon rafting on India as it moved northwards is supported in the case of the Myrtales family Crypteroniaceae [89,114]. One of the most striking, and still unexplained, disjunctions in plant geography is that between Gleditsia amorphoides, a legume tree occurring in Argentina, Bolivia and Paraguay, and its closest living relatives in China [25,115]. This disjunction could either be due to long-distance dispersal across the Pacific, followed by range expansion and extinction, or to migration across Beringia to North America, followed by dispersal from North America to South America and extinction in North America.

\section{Looking for common patterns}

As increasing numbers of disjunctions are analyzed, biogeographers - eager as ever to identify major patterns - are beginning to ask whether the direction and timing of long-distance dispersal events exhibit regularities [103,111,116,117]. Wind and ocean surface currents affect dispersal and, because many wind systems have been stable for geologically relevant periods [118], one expects to find biases in the predominant direction of passive dispersal in spite of lineage-specific differences in dispersal and establishment capability. By combining oceanographic and climatic data with dated phylogenies (chronograms) for many taxa, this expectation should be testable. However, the growing body of evidence suggesting that plants and animals cross dispersal barriers more readily than was previously believed [63,101] implies that only meta-analyses of large samples of studies will have a chance of discovering predominant patterns. Or it might not be that principles derived from island biogeography will be explanatory for the patterns we see today. For example, the common observation that North American clades are nested within Old World radiations might simply be because North America is a fraction of the size of Eurasia and that Eurasia is therefore more likely to serve as the source area for North American clades (M. Lavin, personal communication).

\section{Perspectives}

Controversies about the use of molecular clocks are similar to those about using gene sequences to 'barcode' the identity of organisms. Genetic clocks and barcodes have proven their value, particularly in epidemiology and in the identification of contraband endangered species. When biogeographers can estimate the timing of past events with reasonable accuracy, they will be able to test hypotheses concerning the mechanisms responsible for the distribution of organisms. For this reason, molecular age estimation is an important addition to the tools of biogeography. New data and inferences have enabled biogeographers to assess the likelihood of the antiquity of a lineage or recency in an area. A drawback of most 
current approaches to clock dating is that they do not simultaneously analyze topology, branch lengths and temporal information from the fossil record. In the Bayesian framework, this should become possible, allowing us better age estimates from a combination of fossil and molecular data.

\section{Acknowledgements}

I thank Charles Bell, Olaf Bininda-Emonds, Matthew Lavin, Robert Ricklefs and Frank Rutschmann for helpful comments.

\section{References}

1 Schneider, H. et al. (2004) Ferns diversified in the shadow of angiosperms. Nature $428,553-557$

2 Pennington, R.T. et al. (2004) Plant phylogeny and the origin of major biomes. Philos. Trans. R. Soc. Lond. B Biol. Sci. 359, 1611-1622

3 Crisp, M.D. et al. (2004) Radiation of the Australian flora: what can comparisons of molecular phylogenies across multiple taxa tell us about the evolution of diversity in present-day communities? Philos. Trans. R. Soc. Lond. B Biol. Sci. 359, 1551-1571

4 Pellmyr, O. and Leebens-Mack, J. (1999) Forty million years of mutualism: evidence for Eocene origin of the yucca-yucca moth association. Proc. Natl. Acad. Sci. U. S. A. 96, 9178-9183

5 Becerra, J.X. (2003) Synchronous coadaptation in an ancient case of herbivory. Proc. Natl. Acad. Sci. U. S. A. 100, 12804-12807

6 Datwyler, S.L. and Weiblen, G.D. (2004) On the origin of the fig: phylogenetic relationships of Moraceae from ndhF sequences. Am. J. Bot. 91, 767-777

7 Pennington, R.T. and Dick, C.W. (2004) The role of immigrants in the assembly of the South American rainforest tree flora. Philos. Trans. R. Soc. Lond. B Biol. Sci. 359, 1611-1622

8 Davis, C.C. et al. (2005) Explosive radiation of Malpighiales supports a Mid-Cretaceous origin of modern tropical rain forests. Am. Nat. 165, E36-E65

9 Linder, H.P. and Hardy, C.R. (2004) Evolution of the species-rich Cape flora. Philos. Trans. R. Soc. Lond. B Biol. Sci. 359, 1623-1632

10 Hardy, C.R. and Linder, H.P. (2005) Intraspecific variability and timing in ancestral ecology reconstruction: a test case from the Cape Flora. Syst. Biol. 54, 299-316

11 Crepet, W.L. et al. (2004) Fossil evidence and phylogeny: the age of major angiosperm clades based on mesofossil and macrofossil evidence from Cretaceous deposits. Am. J. Bot. 91, 1666-1682

12 Rydin, C. et al. (2004) On the evolutionary history of Ephedra: Cretaceous fossils and extant molecules. Proc. Natl. Acad. Sci. U. S. A. $101,16571-16576$

13 Carlquist, S. (1983) Intercontinental Dispersal, Parey Vlg

14 Whittaker, R.J. et al. (1997) The re-building of an isolated rain forest assemblage: how disharmonic is the flora of Krakatau? Biodiv Conserv. 6, 1671-1696

15 Avise, J.C. (2000) The History and Formation of Species, Harvard University Press

16 Mack, R.N. et al. (2000) Biotic invasions: causes, epidemiology, global consequences, and control. Ecol. App. 10, 689-710

17 Zuckerkandl, E. and Pauling, L. (1965) Evolutionary divergence and convergence in proteins. In Evolving Genes and Proteins (Bryson, V. and Vogel, H.J., eds), pp. 97-166, Academic Press

18 Wendel, J.F. and Albert, V.A. (1992) Phylogenetics of the cotton genus (Gossypium L.): character-state weighted parsimony analysis of chloroplast DNA restriction site data and its systematic and biogeographic implications. Syst. Biol. 17, 115-143

19 Sang, T. et al. (1994) Radiation of the endemic genus Dendroseris (Asteraceae) in the Juan Fernandez Islands: evidence from sequences of the ITS regions of nuclear ribosomal DNA. Am. J. Bot. $81,1494-1501$

20 Qiu, Y-L. et al. (1995) Molecular divergence in the eastern Asiaeastern North America disjunct section Rytidospermum of Magnolia (Magnoliaceae). Am. J. Bot. 82, 1589-1598

21 Wen, J. and Jansen, R.K. (1995) Morphological and molecular comparisons of Campsis grandiflora and C. radicans (Bignoniaceae), an eastern Asian and eastern North American vicariant species pair. Plant Syst. Evol. 196, 173-183
22 Böhle, U-R. et al. (1996) Island colonization and evolution of the insular woody habit in Echium L. (Boraginaceae). Proc. Natl. Acad. Sci. U. S. A. 93, 11740-11745

23 Lee, N.S. et al. (1996) Molecular divergence between disjunct taxa in eastern Asia and eastern North America. Am. J. Bot. 83, 1373-1378

24 Sang, T. et al. (1997) Chloroplast DNA phylogeny, reticulate evolution, and biogeography of Paeonia (Paeoniaceae). Am. J. Bot. 84, 1120-1136

25 Schnabel, A. and Wendel, J.F. (1998) Cladistic biogeography of Gleditsia (Leguminosae) based on ndhF and rpl16 chloroplast gene sequences. Am. J. Bot. 85, 1753-1765

26 Baum, D.A. et al. (1998) Biogeography and floral evolution of baobabs (Adansonia, Bombacaceae) as inferred from multiple data sets. Syst. Biol. 47, 181-207

27 Baldwin, B.G. and Sanderson, M.J. (1998) Age and rate of diversification of the Hawaiian silversword alliance (Compositae). Proc. Natl. Acad. Sci. U. S. A. 95, 9402-9406

28 Kim, H-G. et al. (1998) Molecular evidence for an African origin of the Hawaiian endemic Hesperomannia (Asteraceae). Proc. Natl. Acad. Sci. U. S. A. 95, 15440-15445

29 Fleischer, R.C. et al. (1998) Evolution on a volcanic conveyor belt: using phylogeographic reconstructions and K-Ar based ages of the Hawaiian Islands to estimate molecular evolutionary rates. Mol. Ecol. 7, 533-545

30 Korber, B. et al. (2000) Timing the ancestor of the HIV-1 pandemic strains. Science 288, 1789-1796

31 Hwang, D.G. and Green, P. (2004) Bayesian Markov chain Monte Carlo sequence analysis reveals varying neutral substitution patterns in mammalian evolution. Proc. Natl. Acad. Sci. U. S. A. 101, 13994-14001

32 Cho, Y. et al. (2004) Mitochondrial substitution rates are extraordinarily elevated and variable in a genus of flowering plants. Proc. Natl. Acad. Sci. U. S. A. 101, 17741-17746

33 Sanderson, M.J. (1998) Estimating rate and time in molecular phylogenies: beyond the molecular clock?. In Molecular Systematics of Plants II: DNA Sequencing (Soltis, D.E. et al., eds), pp. 242-264, Kluwer Academic Publishers

34 Klak, C. et al. (2004) Unmatched tempo of evolution in Southern African semi-desert ice plants. Nature 427, 63-65

35 Bromham, L. et al. (2000) The power of relative rate tests depends on the data. J. Mol. Evol. 50, 296-301

36 Thorne, J.L. et al. (1998) Estimating the rate of evolution of the rate of molecular evolution. Mol. Biol. Evol. 15, 1647-1657

37 Sanderson, M.J. (2002) Estimating absolute rates of molecular evolution and divergence times: a penalized likelihood approach. Mol. Biol. Evol. 19, 101-109

38 Sanderson, M.J. (2003) Molecular data from 27 proteins do not support a Precambrian origin of land plants. Am. J. Bot. 90, 954-956

39 Sanderson, M.J. and Doyle, J.A. (2001) Sources of error and confidence intervals in estimating the age of angiosperms from rbcL and 18S rDNA data. Am. J. Bot. 88, 1499-1516

40 Sanderson, M.J. et al. (2004) Molecular evidence on plant divergence times. Am. J. Bot. 91, 1656-1665

41 Near, T.J. et al. (2005) Assessing concordance of fossil calibration points in molecular clock studies: an example using turtles. Am. Nat. $165,137-146$

42 Siepel, A. and Haussler, D. (2004) Phylogenetic estimation of contextdependent substitution rates by maximum likelihood. Mol. Biol. Evol. 21, 468-488

43 Ané, C. et al. (2005) Covarion structure in plastid genome evolution: a new statistical test. Mol. Biol. Evol. 22, 914-924

44 Bromham, L. and Penny, D. (2003) The modern molecular clock. Nat. Rev. Genet. 4, 216-224

$45 \mathrm{Kim}, \mathrm{S}$. et al. (2004) DNA sequences from Miocene fossils: an ndhF sequence of Magnolia latahensis (Magnoliaceae) and an rbcL sequence of Persea pseudocarolinensis (Lauraceae). Am. J. Bot. 91, 615-620

46 Berry, P.E. et al. (2004) Phylogenetic relationships and biogeography of Fuchsia (Onagraceae) based on noncoding nuclear and chloroplast DNA data. Am. J. Bot. 91, 601-614

47 Zhou, S. et al. Molecular phylogeny and inter- and intracontinental biogeography of Calycanthaceae. Mol. Phyl. Evol. (in press) 
48 Shaul, S. and Graur, D. (2002) Playing chicken (Gallus gallus): methodological inconsistencies of molecular divergence date estimates due to secondary calibration points. Gene 300, 59-61

49 Doyle, J.A. and Donoghue, M.J. (1993) Phylogenies and angiosperm diversification. Paleobiology 19, 141-167

50 Magallón, S. (2004) Dating lineages: molecular and paleonotological approaches to the temporal framework of clades. Int. J. Plant Sci. $165, \mathrm{~S} 7-\mathrm{S} 21$

51 Scheen, A-C. et al. (2004) Northern hemisphere biogeography of Cerastium (Caryophyllaceae): insights from phylogenetic analysis of noncoding plastid nucleotide sequences. Am. J. Bot. 91, 943-952

52 Gottschling, M. et al. (2004) Testing hypotheses on disjunctions present in the primarily woody Boraginales: Ehretiaceae, Cordiaceae, and Heliotropiaceae, inferred from ITS1 sequence data. Int. J. Plant Sci. 165(4 Suppl.), S123-S135

53 Sytsma, K.J. et al. (2004) Clades, clocks, and continents: historical and biogeographical analysis of Myrtaceae, Vochysiaceae, and relatives in the southern hemisphere. Int. J. Plant Sci. 165(4 Suppl.), S85-S105

54 Bell, C.D. and Donoghue, M.J. (2005) Dating the Dipsacales: comparing models, genes, and evolutionary implications. Am. J. Bot. 92, 284-296

55 Bell, C.D. and Donoghue, M.J. (2005) Phylogeny and biogeography of Valerianaceae (Dipsacales) with special reference to the South Ameircan valerians. Org. Divers. Evol. 5, 147-159

56 Richardson, J.E. et al. (2001) Rapid and recent origin of species richness in the Cape flora of South Africa. Nature 412, 181-183

57 Rønsted, N. et al. (2002) Phylogenetic relationships within Plantago (Plantaginaceae): evidence from nuclear ribosomal ITS and plastid trnL-F sequence data. Bot. J. Linn. Soc. 139, 323-338

58 Lindqvist, C. and Albert, V.A. (2002) Origin of the Hawaiian endemic mints within North American Stachys (Lamiaceae). Am. J. Bot. 82, $1709-1724$

59 Howarth, D.G. et al. (2003) Phylogenetics of the genus Scaevola (Goodeniaceae): implication for dispersal patterns across the Pacific Basin and colonization of the Hawaiian Islands. Am. J. Bot. 90, 915923

60 Clement, W.L. et al. (2004) Phylogenetic position and biogeography of Hillebrandia sandwicensis (Begoniaceae): a rare Hawaiian relict. Am. J. Bot. 91, 905-917

61 Saporta, G.d. (1865) Etudes sur la végétation du Sud-Est de la France a l'époche tertiaire. Ann. Sci. Nat. Bot. Ser. 5, 5-264

62 Zhang, L-B. et al. Phylogeny of the Cucurbitales based on DNA sequences of nine loci from three genomes: implications for morphological and sexual system evolution. Mol. Phylo. Evol. (in press)

63 DeQueiroz, A. (2004) The resurrection of oceanic dispersal in historical biogeography. Trends Ecol. Evol. 20, 68-73

64 Schneider, H. et al. (2005) Origin of the endemic fern genus Diellia coincides with the renewal of Hawaiian terrestrial life in the Miocene. Proc. R. Soc. Lond. B. Biol. Sci. 272, 455-460

65 Mansion, G. and Zeltner, L. (2004) Phylogenetic relationships within the New World endemic Zeltnera (Gentianaceae-Chironiinae) inferred from molecular and karyological data. Am. J. Bot. 91, 2069-2086

66 Huang, J. and Price, R.A. (2003) Estimation of the age of extant Ephedra using chloroplast rbcL sequence data. Mol. Biol. Evol. 20, 435-440

67 Zhang, L-B. and Renner, S.S. (2003) The deepest splits in Chloranthaceae as resolved by chloroplast sequences. Int. J. Plant Sci. 164(5 Suppl.), S383-S392

68 Knapp, M. et al. (2005) Relaxed molecular clock provides evidence for long-distance dispersal of Nothofagus (Southern Beech). PLoS Biol. $3,38-43$

69 Yoo, M-J. et al. Estimation of divergence times and biogeography of major clades of Nymphaeales. Syst. Bot. (in press)

70 Kimball, R.T. et al. (2003) Out of Africa: molecular phylogenetics and biogeography of Wolffiella (Lemnaceae). Biol. J. Linn. Soc. 79, 565576

71 Les, D.H. et al. (2003) Biogeography of discontinuously distributed hydrophytes: a molecular appraisal of intercontinental disjunctions. Int. J. Plant Sci. 164, 917-932
72 Renner, S.S. and Zhang, L-B. (2004) Biogeography of the Pistia clade (Araceae): based on chloroplast and mitochondrial DNA sequences and Bayesian divergence time inference. Syst. Biol. 53, 422-432

73 Sanderson, M.J. (1997) A nonparametric approach to estimating divergence times in the absence of rate constancy. Mol. Biol. Evol. 14, $1218-1231$

74 Rambaut, A. and Bromham, L. (1998) Estimating divergence dates from molecular sequences. Mol. Biol. Evol. 15, 442-448

75 Aris-Brosou, S. and Yang, Z. (2002) Effects of models of rate evolution on estimation of divergence dates with special reference to the metazoan 18S rRNA phylogeny. Syst. Biol. 51, 703-714

76 Yang, Z. and Yoder, A.D. (2003) Comparison of likelihood and Bayesian methods for estimating divergence times using multiple gene loci and calibration points, with application to a radiation of cute-looking mouse lemur species. Syst. Biol. 52, 705-716

77 Sanderson, M.J. (2003) R8s: inferring absolute rates of molecular evolution and divergence times in the absence of a molecular clock. Bioinformatics 19, 301-302

78 Lavin, M. et al. (2004) Metacommunity process rather than continental tectonic history better explains geographically structured phylogenies in legumes. Philos. Trans. R. Soc. Lond. B Biol. Sci. 359, 1509-1522

79 Richardson, J.E. et al. (2004) Historical biogeography of two cosmopolitan families of flowering plants: Annonaceae and Rhamnaceae. Philos. Trans. R. Soc. Lond. B Biol. Sci. 359, 1495-1508

80 Lavin, M. et al. (2005) Evolutionary rates analysis of Leguminosae implicates a rapid diversification of lineages during the Tertiary. Syst. Biol. 54, 000-000

81 Yoder, A.D. and Yang, Z. (2000) Estimation of primate speciation dates using local molecular clocks. Mol. Biol. Evol. 17, 1081-1090

82 Pérez-Losada, M. et al. (2004) Unraveling the evolutionary radiation of the Thoracican barnacles using molecular and morphological evidence: a comparison of several divergence time estimation approaches. Syst. Biol. 53, 244-264

83 Baum, D.A. et al. (2004) Phylogenetic relationships of Malvatheca (Bombacoideae and Malvoideae; Malvaceae sensu lato) as inferred from plastid DNA sequences. Am. J. Bot. 91, 1863-1871

84 Kishino, H. et al. (2001) Performance of a divergence time estimation method under a probabilistic model of rate evolution. Mol. Biol. Evol. $18,352-361$

85 Thorne, J.L. and Kishino, H. (2002) Divergence time estimation and rate evolution with multilocus data sets. Syst. Biol. 51, 689-702

86 Ho, S.Y.W. et al. (2005) Accuracy of rate estimation using relaxedclock models with a critical focus on the early metazoan radiation. Mol. Biol. Evol. 22, 1355-1363

87 Wiegmann, B.M. et al. (2003) Time flies, a new molecular time-scale for brachyceran fly evolution without a clock. Syst. Biol. 52, 745-756

88 Renner, S.S. (2004) Multiple Miocene Melastomataceae dispersal between Madagascar, Africa, and India. Philos. Trans. R. Soc. Lond. B Biol. Sci. 359, 1485-1494

89 Rutschmann, F. et al. (2004) Did Crypteroniaceae really disperse outof-India? Molecular dating evidence from rbcL, ndhF, and $\mathrm{rpl} 16$ intron sequences. Int. J. Plant Sci. 165(4 Suppl.), S69-S83

90 Douzery, E.J.P. et al. (2004) The timing of eukaryotic evolution: does a relaxed molecular clock reconcile proteins and fossils? Proc. Natl. Acad. Sci. U. S. A. 101, 15386-15391

91 Linder, H.P. et al. (2005) Taxon sampling effects in molecular clock dating: an example from the African Restionaceae. Mol. Phylogenet. Evol. 35, 569-582

92 Renner, S.S. and Meyer, K. (2001) Melastomeae come full circle: biogeographic reconstruction and molecular clock dating. Evolution Int. J. Org. Evolution 55, 1315-1324

93 Renner, S.S. et al. (2001) Historical biogeography of Melastomataceae: the roles of Tertiary migration and long-distance dispersal. Am. J. Bot. 88, 1290-1300

94 Britton, T. et al. (2002) Phylogenetic dating with confidence intervals using mean path lengths. Mol. Phylogenet. Evol. 42, 58-65

95 Wen, J. (1999) Evolution of eastern Asian and eastern North American disjunct distributions in flowering plants. Annu. Rev. Ecol. Syst. 30, 421-455

96 Xiang, Q-Y. et al. (2000) Timing the Eastern Asian-Eastern North American floristic disjunction: molecular clock corroborates paleontological estimates. Mol. Phylogenet. Evol. 15, 462-472 
97 Renner, S.S. et al. (2004) A chloroplast phylogeny of Arisaema (Araceae) illustrates Tertiary floristic links between Asia, North America, and East Africa. Am. J. Bot. 91, 881-888

98 Nie, Z-L. et al. (2005) Monophyly of Kelloggia Torrey ex Benth. (Rubiaceae) and evolution of its intercontinental disjunction between western North America and eastern Asia. Am. J. Bot. 92, 642-652

99 Chanderbali, A.S. et al. (2001) Phylogeny and historical biogeography of Lauraceae: evidence from the chloroplast and nuclear genomes. Ann. Mo. Bot. Gard. 88, 104-134

100 Davis, C.C. et al. (2002) Laurasian migration explains Gondwanan disjunctions: evidence from Malpighiaceae. Proc. Natl. Acad. Sci. U. S. A. 99, 6833-6837

101 McGlone, M.S. (2005) Goodbye Gondwana. J. Biogeogr. 32, 739-740

102 Pole, M.S. (2001) Can long-distance dispersal be inferred from the New Zealand plant fossil record? Aust. J. Bot. 49, 357-366

103 Winkworth, R.C. et al. (2002) Plant dispersal N.E.W.S from New Zealand. Trends Ecol. Evol. 17, 514-520

104 Bartish, G.V. et al. (2005) Phylogenetic relationships among New Caledonian Sapotaceae (Ericales): molecular evidence for generic polyphyly and repeated dispersal. Am. J. Bot. 92, 667-673

105 Winkworth, R.C. et al. (2002) The origins and evolution of the genus Myosotis L. (Boraginaceae). Mol. Phylogenet. Evol. 24, 180-193

106 Mummenhoff, K. et al. (2004) Molecular evidence for bicontinental hybridogenous genomic constitution in Lepidium sensu stricto (Brassicaceae) species from Australia and New Zealand. Am. J. Bot. 91, 254-261

107 Renner, S.S. (2004) Bayesian analysis of combined data partitions, using multiple calibrations, supports recent arrival of Melastomataceae in Africa and Madagascar. Am. J. Bot. 88, 1290-1300

108 Dick, C.W. et al. (2003) Molecular systematic analysis reveals cryptic Tertiary diversification of a widespread tropical rain forest tree. Am. Nat. 162, 691-703

109 Givnish, T.J. et al. (2004) Ancient vicariance or recent long-distance dispersal? Inferences about phylogeny and South American-African disjunctions in Rapateaceae and Bromeliaceae based on ndhF sequence data. Int. J. Plant Sci. 165(4 Suppl.), S35-S54
110 Coleman, M. et al. (2003) Repeat intercontinental dispersal and Pleistocene speciation in disjunct Mediterranean and desert Senecio (Asteraceae). Am. J. Bot. 90, 1446-1454

111 Renner, S.S. (2004) Plant dispersal across the tropical Atlantic by wind and sea currents. Int. J. Plant Sci. 165(4 Suppl.), S23-S33

112 Malcomber, S.T. (2002) Phylogeny of Gaertnera Lam. (Rubiaceae) based on multiple DNA markers: evidence of a rapid radiation in a widespread, morphologically diverse genus. Evol. Int. J. Org. Evol. $56,42-57$

113 Yuan, Y-M. et al. (2005) Phylogeny and biogeography of Exacum (Gentianaceae): a disjunctive distribution in the Indian Ocean basin resulted from long distance dispersal and extensive radiation. Syst. Biol. 54, 21-34

114 Conti, E. et al. (2004) Calibration of molecular clocks and the biogeographic history of Crypteroniaceae: a reply to Robert G. Moyle. Evol. Int. J. Org. Evol. 58, 1874-1876

115 Schnabel, A. et al. (2003) Phylogenetic relationships in Gleditsia (Leguminosae) based on ITS sequences. Am. J. Bot. 90, 310-320

116 Sanmartín, I. and Ronquist, F. (2004) Southern Hemisphere biogeography inferred by event-based models: plant versus animal patterns. Syst. Biol. 53, 216-243

117 Cook, L.G. and Crisp, M.D. (2005) Directional asymmetry of longdistance dispersal and colonization could mislead reconstructions of biogeography. J. Biogeogr. 32, 741-754

118 Muñoz, J. et al. (2004) Wind as a long-distance dispersal vehicle in the Southern Hemisphere. Science 304, 1144-1147

119 Won, H. and Renner, S.S. Bayesian relaxed clock estimates suggest that the gymnosperm genus Gnetum (Gnetales) dispersed over water between South America, Africa, and Asia. Syst. Biol. (in press)

120 Welch, J.J. and Bromham, L. (2005) Molecular dating when rates vary. Trends Ecol. Evol. 20,320-327

121 Rutschmann, F. Molecular dating of phylogenetic trees: a brief review of current methods that estimate divergence times. Div. Distrib. (in press)

\section{AGORA initiative provides free agriculture journals to developing countries}

The Health Internetwork Access to Research Initiative (HINARI) of the WHO has launched a new community scheme with the UN Food and Agriculture Organization.

As part of this enterprise, Elsevier has given 185 journals to Access to Global Online Research in Agriculture (AGORA). More than 100 institutions are now registered for the scheme, which aims to provide developing countries with free access to vital research that will ultimately help increase crop yields and encourage agricultural self-sufficiency.

According to the Africa University in Zimbabwe, AGORA has been welcomed by both students and staff. 'It has brought a wealth of information to our fingertips' says Vimbai Hungwe. 'The information made available goes a long way in helping the learning, teaching and research activities within the University. Given the economic hardships we are going through, it couldn't have come at a better time.'

For more information visit:

http://www.healthinternetwork.net 